Reprod. Nutr. Dévelop., 1988, 28 Suppl. n¹, 145-146

\title{
Modification de l'ingestion et de l'abreuvement après occlusion duodénale expérimentale chez le mouton
}

H. BRUGERE, R. ZEMIRLINE

Ecole Nationale Vétérinaire

94704 Maisons-Alfort Cedex, France.

Summary. A duodenal occlusion was performed near the pylorus in 10 sheep fed hay ad libitum and barley $(350 \mathrm{~g} /$ day). The first day, grain intake ceased and a $60 \%$ decrease in forage and water intake occurred. Hay intake approached zero on day 4, but some water intake persisted, probably because of the continuation of diuresis.

L'occlusion digestive en région pylorique produit un reflux du contenu abomasal dans le réticulo-rumen. II en résulte un ensemble de modifications qui concernent l'appareil digestif, les métabolismes et l'équilibre acido-basique (Kuiper, 1980). Nous rapportons ici les effets induits par ce type d'occlusion sur l'ingestion d'aliments et d'eau chez le mouton.

Matériel et méthodes. L'étude a porté sur dix moutons d'un poids moyen de $33,8 \pm 3,8 \mathrm{~kg}$ qui ont tout d'abord, été pourvus d'une fistule du rumen et d'une ligature placée, mais non serrée, en aval du pylore. Après rétablissement, les animaux étaient installés dans une cage à métabolisme où ils recevaient une fois par jour du foin de graminées ad libitum et des céréales $(350 \mathrm{~g} / \mathrm{j}$ au maximum d'orge). Les ingérés et les excrétats étaient mesurés chaque matin ainsi qu'une trentaine de paramètres biochimiques usuels, pendant la période témoin, puis après serrage de la ligature dans la période d'occlusion (Zemirline, 1987).

Résultats et discussion. Parmi les modifications observées, celles des comportements ingestif et dipsique ont été parmi les plus précoces. Elles surviennent avant les modifications métaboliques (tabl. 1). L'ingestion d'aliment chute brutalement au cours des premières $24 \mathrm{~h}$. Pour la ration de foin, la réduction est de $60 \%$ le premier jour après quoi la baisse s'accentue (ingestion de quantités négligeables à $\mathrm{J} 3$ et $\mathrm{J} 4$ ). Pour la ration de céréales, l'arrêt de l'ingestion est immédiat. Parmi les mécanismes de cette anorexie, on peut incriminer la distension de l'ensemble abomasum et réticulo-rumen, mais celle-ci est très modérée au cours des premières $24 \mathrm{~h}$. La baisse du $\mathrm{pH}$ du rumen, environ 0,75 unité, n'est pas non plus assez marquée pour être responsable de l'anorexie. L'effet des acides sur les récepteurs de la muqueuse du rumen résulte de l'action des acides gras volatils (AGV) non dissociés (Crichlow et Leek, 1986), ce qui implique un $\mathrm{pH}$ très bas (par exemple $<5,5$ ). Ici, de plus, la concentration en AGV totaux a diminué régulièrement. La motricité du rumen a présenté une baisse importante, environ $60 \%$ après $48 \mathrm{~h}$, qui peut être attribuée à la disparition progressive des fibres. L'ingestion d'eau décroît de $58 \%$ le premier jour. A la 
différence de l'ingestion d'aliments, elle ne s'annule jamais, et présente d'importantes fluctuations d'un jour à l'autre. Cette réduction de l'abreuvement est en opposition avec le développement chez les animaux de deux stimulus de la soif : l'hypovolémie et la déshydratation du territoire extra-cellulaire dont témoigne par exemple l'élévation du temps de persistance du pli cutané. La pression osmotique sanguine, estimée à partir des concentrations de solutés (Green, 1978) ne présente qu'une faible élévation au cours de la période d'observation. L'évolution du volume urinaire suggère que la persistance de l'abreuvement soit liée à celle d'un certain niveau de diurèse.

TABL. 1. - Evolution des quantités d'aliments et d'eau ingérées après occ/usion duodénale haute (Moyennes et écarts-types - P.T. = période témoin $-J_{1}$ à $J_{4}=$ période post-occlusion).

\begin{tabular}{lccccc}
\hline Paramètres & P.T. & $\mathrm{J}_{1}$ & $\mathrm{~J}_{2}$ & $\mathrm{~J}_{3}$ & $\mathrm{~J}_{4}$ \\
\hline Ingestion de foin (g/l) & $620(19)$ & $210(170)$ & $100(130)$ & $40(40)$ & $20(50)$ \\
Ingestion d'orge (g/l) & $327(56)$ & $4(8)$ & 0 & 0 & 0 \\
Ingestion d'eau (ml/l) & $650(260)$ & $270(330)$ & $140(220)$ & $110(150)$ & $250(90)$ \\
$\begin{array}{l}\text { Contractions du rumen } \\
\text { (Nbre pour 10 min) }\end{array}$ & $21,6(1,5)$ & $13,3(5,0)$ & $8,8(4,7)$ & $9,7(3,3)$ & $8,9(3,9)$ \\
pH du contenu ruminal (u.) & 7,9 & 7,4 & 7,4 & 7,4 & 7,4 \\
$\begin{array}{l}\text { Acides gras volatils } \\
\text { (mmoles/l) }\end{array}$ & $78,9(29,1)$ & $61,2(14,6)$ & $54,1(20,3)$ & $45,1(18,9)$ & $31,9(17,6)$ \\
Volume urinaire (ml/j) & $694(256)$ & $299(25,3)$ & $276(180)$ & $180(117)$ & $169(82)$ \\
$\begin{array}{l}\text { Osmolatité plasmatique } \\
\text { (mOsm/l) }\end{array}$ & $290(14,7)$ & $292(22,0)$ & $293(19,2)$ & $295(17,6)$ & $299(32,0)$ \\
Persistance pli cutané (s) & $1(0)$ & $1(0)$ & $2,3(1,7)$ & $4,4(2,2)$ & $6,6(2,9)$ \\
\hline
\end{tabular}

En conc/usion, l'occlusion digestive haute chez le mouton provoque rapidement un tableau d'aphagie-adipsie dont les mécanismes restent à élucider. Les modifications produites dans le réticulo-rumen par le reflux du liquide abomasal (baisse du $\mathrm{pH}$, distension des réservoirs gastriques) ne semblent pas atteindre une amplitude suffisante pour en être responsables, alors que paradoxalement s'installent des modifications métaboliques (baisse de production et d'absorption des acides gras volatils, déshydratation) qui devraient constituer des facteurs de stimulation de l'ingestion et de l'abreuvement.

Crichlow E. C., Leek B. F., 1986. Forestomach epithelial receptor infusions of volatile fatty acids. $A m$. J. vet. Res., 47, 1015-1018.

Green R. A., 1978. Perspectives of clinical osmometry. Vet. Clin. North Am., 8, 287-299.

Kuiper R., 1980. Reflux van lebmaaginhound bij het rund. Thèse Doc. Vet. Utrecht.

Zemirline R., 1987. Occlusion duodénale expérimentale chez les petits ruminants. Thèse Doc. III cycle. Univ. Paris VI. 